\title{
Large cavitary dead space as an unusual cause of hypercapnic respiratory failure in pulmonary tuberculosis
}

\author{
DEBORAH SHURE, ROGER G SPRAGG, KENNETH M MOSER
}

From the Division of Pulmonary and Critical Care Medicine, San Diego School of Medicine, San Diego, California

While respiratory failure has been reported in miliary tuberculosis, ${ }^{2}$ acute cavitary pulmonary tuberculosis is not commonly associated with hypercapnic respiratory failure. We report here a patient in whom persistent respiratory failure did develop, the mechanism being shown to be a large, well-ventilated cavity that created a significant ventilatory dead space.

\section{Case report}

A 21-year-old Mexican man was admitted to University Hospital with a six-month history of fever, cough, weight loss, and increasing shortness of breath. A family member had had isoniazid-resistant pulmonary tuberculosis.

The physical examination showed cachexia, temperature of $38.3^{\circ} \mathrm{C}$, blood pressure $95 / 65 \mathrm{~mm} \mathrm{Hg}$, clubbing, amphoric breath sounds over the left upper lobe, and wheezes over the rest of his lungs. His chest radiograph (fig 1) showed bilateral upper lobe cavities, the left much larger than the right, and diffuse infiltrates in the rest of the lung compatible with bronchogenic spread of tuberculosis. The sputum was strongly positive for acid-fast bacilli and later Mycobacterium tuberculosis, sensitive to all first-line drugs, was cultured.

Shortly after admission the patient sustained a cardiopulmonary arrest, from which he was resuscitated after endotracheal intubation. Because of his moribund condition and the history of exposure to isoniazid-resistant tuberculosis, he was treated initially with methylprednisolone, isoniazid, rifampin, pyrazinamide, ethambutol, and streptomycin. Mechanical ventilation was continued.

The patient's condition stabilised over the next week. His infiltrates began to clear and his sputum was culture negative two weeks after the start of treatment, although it remained heavily positive on smear. Repeated attempts were made to wean the patient from the ventilator both by tapering the intermittent mandatory ventilation (IMV) rate and by conventional weaning techniques (using a T-piece with supplemental oxygen), but mechanical ventilation had to be maintained because of severe hypercapnia-arterial carbon dioxide tension $\left(\mathrm{PaCO}_{2}\right)$ $8 \cdot 0-9 \cdot 3 \mathrm{kPa}(60-70 \mathrm{~mm} \mathrm{Hg})$-despite minute ventilation volumes $\left(\dot{V}_{E}\right)$ of 20-24 litres a minute. His arterial oxygen tension $\left(\mathrm{PaO}_{2}\right)$ was maintained in the range of 9.3-10.7 $\mathrm{kPa}(70-80 \mathrm{~mm} \mathrm{Hg})$ with a fractional inspired oxygen value $\left(\mathrm{FIO}_{2}\right)$ of 0.35 .

Address for reprint requests: Dr Deborah Shure, University of California San Diego Medical Center, 225 Dickinson Street, San Diego, California 92103, USA

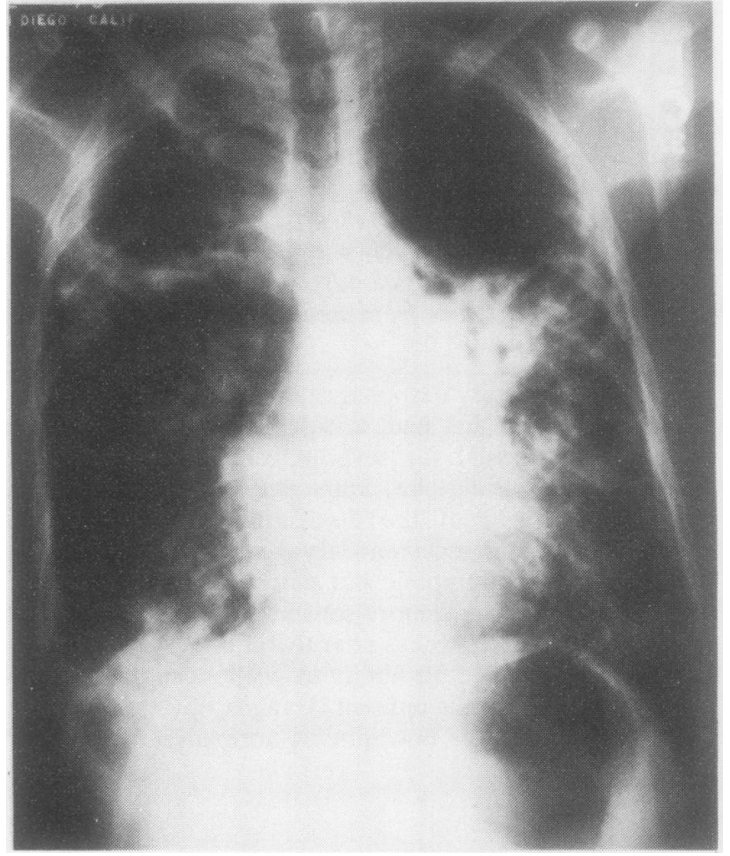

Fig 1 Chest radiograph on admission, showing bilateral upper lobe cavities and lower lobe inflitrates.

On his 30th day in hospital quantitative ventilation/ perfusion (V/Q) lung scanning was performed using ${ }_{99 m}$ technetium-labelled macroaggregated albumin and ${ }^{133 \mathrm{~m}}$ xenon-labelled gas (fig 2). The scans showed that while the left upper lobe cavity was not perfused, it filled more rapidly and emptied more completely than the rest of the patient's lung. The calculated $V / Q$ ratio in the left upper lobe was $4 \cdot 5$ times that of the upper right lobe. The following day a balloon-tipped catheter was positioned in the left upper lobe bronchus under fibreoptic bronchoscopic guidance with the patient maintained on mechanical ventilation in an IMV mode. The balloon was inflated to occlude the upper lobe but not the lingula, and the bronchoscope was removed. The patient's arterial blood showed $\mathrm{pH} 7 \cdot 41$, $\mathrm{PaCO}_{2} 11.2 \mathrm{kPa}(84 \mathrm{~mm} \mathrm{Hg})$, and $\mathrm{PaCO}_{2} 7.9 \mathrm{kPa}(59 \mathrm{~mm}$ $\mathrm{Hg}$ ) on a ventilator with an $\mathrm{FIO}_{2} 0 \cdot 35$, an IMV rate of 15 breaths a minute with a tidal volume of $700 \mathrm{ml}$, and a spontaneous ventilatory rate of 40 breaths a minute with a tidal volume of $350 \mathrm{ml}$. The total $\dot{\mathrm{V}}_{\mathrm{E}}$ was 24.5 litres a minute. A few minutes after balloon occlusion of the left 


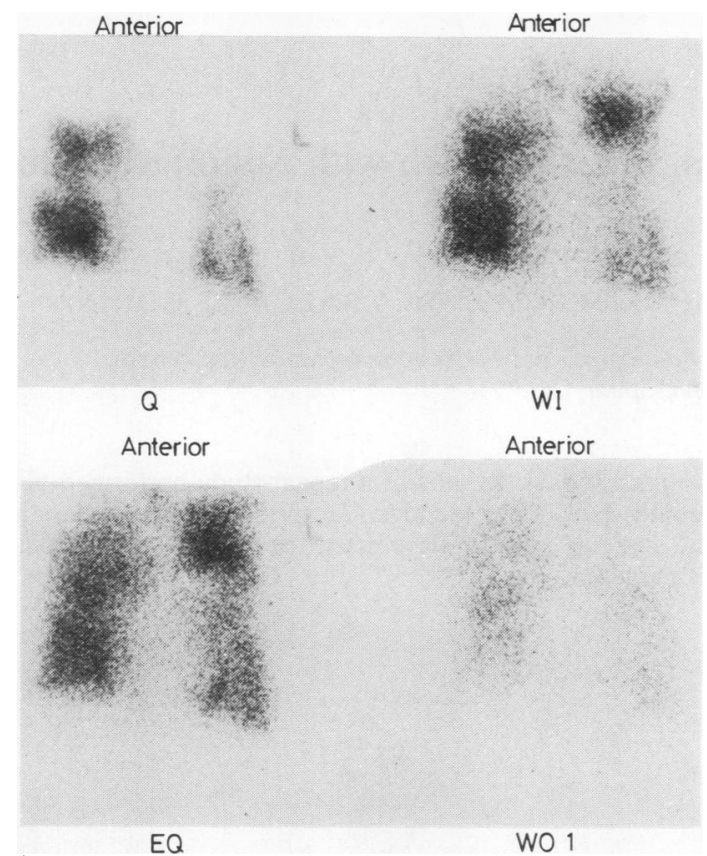

Fig 2 Perfusion scan (Q) showing no perfusion to either upper lobe cavity. Ventilation scan in washin (WI), equilibrium (EQ), and washout (WO 1) phases showing rapid filling and emptying of the left upper lobe cavity with diffuse hang-up of ventilation in the rest of the lung.

upper lobe the patient fell asleep and his spontaneous respirations ceased. (This phenomenon has been observed in people for whom the work of breathing is suddenly decreased.) Fifteen minutes after balloon occlusion the arterial blood gas was $\mathrm{pH} 7 \cdot 46, \mathrm{PaO}_{2} 14 \cdot 1 \mathrm{kPa}(106 \mathrm{~mm}$ $\mathrm{Hg}), \mathrm{PaCO}_{2} 6.3 \mathrm{kPa}(47 \mathrm{~mm} \mathrm{Hg})$ with the same ventilator settings listed above. The $\dot{\mathrm{V}}_{\mathrm{E}}$ was 10.5 litres a minute.

\section{Discussion}

Active pulmonary tuberculosis is not commonly con- sidered as a cause of hypercapnic respiratory failure. The data available have indicated that the $V / Q$ disturbances that occur with tuberculosis are well matched and therefore do not perturb gas exchange significantly..$^{3-5}$ Recently, however, Agarwal ${ }^{6}$ reported a $1.6 \%$ incidence of respiratory failure in acute non-miliary tuberculosis. Most of their patients had hypercapnia as well as hypoxaemia. Their data suggest that significant $V / Q$ abnormalities can exist in active pulmonary tuberculosis.

The present report supports the findings of Agarwal ${ }^{6}$ but in this case relates the physiological abnormality to a large cavitary dead space. The V/Q scan showed that the left upper lobe cavity was a major site of wasted ventilation, and the technique of balloon occlusion of the involved area confirmed its contribution. The fact that the $V / Q$ scan showed diffusely slow washout in the rest of the lung, and that slight hypercapnia persisted after balloon occlusion of the left upper lobe, suggests that the patient has diffuse $\mathrm{V} / \mathrm{Q}$ abnormalities as well. The dramatic fall in $\dot{V}_{E}$ and $\mathrm{PaCO}_{2}$ with balloon occlusion, however, indicates that the major problem was the wasted ventilation of the left upper lobe cavity. This case also suggests that it may be worth looking for problems arising from localised dead space in pulmonary tuberculosis and that the two techniques used in this case, V/Q lung scanning and bronchoscopically guided selective bronchial occlusion, may be useful ones to apply in similar cases. This may be true not only in the acute case but also in preoperative evaluation for potential thoracic surgical intervention, an approach which is planned in this patient.

\section{References}

' Homan W, Harman E, Braun NMT, Felton CP, King TKC, Smith JP. Miliary tuberculosis presenting as acute respiratory failure: Treatment by membrane oxygenator and ventricle pump. Chest 1975;67:366-9.

${ }^{2}$ Huseby JS, Hudson LD. Miliary tuberculosis and adult respiratory distress syndrome. Ann Intern Med 1976;85:609-11.

${ }^{3}$ Bromberg PA, Robin ED. Abnormalities of lung function in tuberculosis. Adv Tuberc Res 1963;12:1-27.

4 Simpson EG, Kuschner M, McClement J. Respiratory function in pulmonary tuberculosis. Am Rev Respir Dis 1963;87:1-16.

${ }^{5}$ Blair E, Hickman JB. Quantitative study of intrapulmonary gas mixing in pulmonary tuberculosis. Am Rev Tuberc 1956;74:343-50.

- Agarwal MK, Muthuswamy PP, Banner AS, Shah RS, Addington WW. Respiratory failure in pulmonary tuberculosis. Chest 1977;72:605-9. 